ARTICLE

DOI: $10.1057 /$ s41599-017-0047-7

\title{
How can we use the 'science of stories' to produce persuasive scientific stories?
}

\author{
Michael D. Jones ${ }^{1} \&$ Deserai Anderson Crow ${ }^{2}$
}

\begin{abstract}
The core goal of the science communicator is to convey accurate scientific information-to help people update existing understandings of the world and to change those understandings when necessary. However, science communicators, with their often extensive scientific training and educations, are often socialized into educating with information derived from scientific works in a way that mirrors the values of science itself. They do this by primarily relying on an approach termed the Knowledge Deficit Model, a model of communicating that emphasizes the repetition of emotionless objectively sterile information to increase understanding. The problem with this approach is that people do not actually make decisions or process information based on only objective scientific evidence. Their personal beliefs and emotional understandings of the world also play a powerful role. In this article we argue that to better connect with audiences communicators would do well to recognize themselves as storytellers-not to distort the truth, but to help people to connect with problems and issues on a more human level in terms of what matters to them. We reference extant narrative persuasion scholarship in public policy and elsewhere to offer a step-by-step guide to narrating scientific evidence. We argue that through understanding the structure of a narrative, science communicators can engage in the policy process, remaining true to the tenets of science and maintaining the integrity of the evidence, but doing so in a way that is compelling and thus also effective in helping solve problems.
\end{abstract}

\footnotetext{
${ }^{1}$ School of Public Policy, Oregon State University, 100D Bexell Hall, Corvallis, OR 97330, USA. ${ }^{2}$ School of Public Affairs, University of Colorado, Denver, Campus Box 142, P.O. Box 173364, CO 80217-3362, USA. Correspondence and requests for materials should be addressed to

M.D.J. (email: Michael.Jones@oregonstate.edu)
} 


\section{Introduction}

W hen communicating complex topics that often include scientific information, policy actors, scientists and other experts can more effectively communicate if they overtly embrace the idea that they are narrating these topics. By so doing, individuals recognize themselves as storytellers and tap the most human of instincts to relay information, capture attention, and persuade audiences. Through understanding how a narrative can be developed to facilitate more effective communication, science communicators can engage in the policy process, remaining true to the tenets of science and maintaining the integrity of scientific evidence, but doing so in a way that is also compelling and thus effective in helping solve problems. For these purposes, we draw on the Narrative Policy Framework (NPF) (Shanahan et al., 2017) to define narratives as having a setting, characters, plot, and moral. The NPF draws on this understanding of narratives to examine how they can be employed to influence policymaking. Here we draw on NPF scholarship to identify key aspects of storytelling that actors can use to maximize attention to, or the uptake of, scientific evidence in policymaking.

\section{Shortcomings of knowledge deficit science communication}

When we seek to generate more effective scientific communication, we are asking of communicators that they convey a correct scientific understanding of the world. For our purposes, we understand scientific evidence in this context to mean "an argument or assertion backed by information...", whereas that information is produced via the scientific method (Cairney, 2016, p 3). Correct, in this context, refers to the most rigorous findings available. The task then is to imbed agreed upon scientific evidence within communications in a way that persuades individuals that interact with the communications to regard said evidence as legitimate and memorable. The primary way this has been done over the years is to repeatedly present the most rigorous scientific evidence available until the science wins over the intended audience. This is what is known as the knowledge deficit model (KDM). While this model has yielded some success (e.g., Reynolds et al., 2010), there is considerable scholarship documenting its deficiencies. In short, we know that scientific evidence is important, but it is not sufficient in most cases to persuade on its own.

Our first example of KDM's shortcomings can be found in the utilization literature, which focuses on the effectiveness of policy analyses and evaluation in influencing public policy. Policy sciences are born of the scientific method, following linear problem solving rubrics (e.g., Bardach and Patashnik, 2015), leveraging the best methodologies (Lasswell, 1970), usually in pursuit of the most rational solutions (e.g., Weimer and Vining, 2017). Policy analysts and evaluators operating within government agencies, think tanks, independent shops, and within non-profit sectors have leveled forests over the years producing what they believe are the best possible solutions- the most rational and scientificto the most complex problems facing humanity. Much of what is produced by these yeomen efforts never finds its way into public policy. This problem, dubbed the problem of utilization, is an old one (Lynd, 1939).

Despite volume upon volume of pertinent scientific studies and analyses related to public policy, findings are regularly ignored (e.g., Kirkhart, 2000), or when used, they are frequently misused (Stevens and Dial, 1994), often for strategic or political purposes (Stone, 2011). That is not to say that policy analysis is never a factor in policy decisions. It is, especially in the process of deliberation that precedes policy (Monaghan, 2010; Stevens, 2007) or when research is introduced into low to moderate conflict forums governed by strong professional norms that favor science (see Weible, 2008). But the academic discipline of public policy has long felt the frustration of knowing that it is more than simply "the best science" that drives policy; rather, the belief systems of the person encountering the scientific evidence (Sabatier and Jenkins-Smith, 1993) and whether or not it serves their policy goals have also been shown to play a powerful role (Stone, 2011), often overwhelmingly so. Studies focusing specifically on science communication help illuminate the "why" in the problem of utilization.

Science communication scholars have studied the gap between expert and lay opinion since at least 1970 (Kahan, 2014) with recent forays into the subject covering an array of issues including climate change (Jones, 2014a), nuclear energy (Stoutenborough et al., 2013), and vaccines (Song, 2014), to name but a few. Findings in this body of literature have illuminated several potential drivers of why science alone cannot close the gap between expert and lay understandings of these various issues. The general idea of what these scholars are finding can be summed up with the concept of biased assimilation, which is a process by which people tend to engage new information in a way that affirms their existing understanding of the world, and themselves (e.g., Kahan et al., 2007). Biased assimilation findings show that individuals tend to seek out and accept information that affirms their identities (e.g., Stroud, 2008) and tend to reject information that does not (Taber and Lodge, 2006). Moreover, findings examining bias assimilation also observe that this process is not moderated by higher levels of education or expertize. In fact, the exact opposite occurs. The more educated somebody is, the more powerful the biases (Taber and Lodge, 2006). The science communication literature has also gone far in assessing some of the underlying factors that structure these biases, finding that belief systems (e.g., Dunlap et al., 2000), culture (e.g., Kahan et al., 2011) and ideology (e.g., Jones, 2011) are all identity defining characteristics that play a powerful role in shaping how people process incoming information, thus inhibiting the effectiveness of KDM. In sum, while KDM has had some successes, much of what we see in terms of knowledge utilization and science communication indicates that those successes might simply be serendipitous.

Western culture has fetishized objective expertize for most of the past century, which has helped enshrine KDM in our political processes. The political sphere broadly, and policymaking in particular, have become venues within which expertize dominates discussion over what are often actually values-based trade-offs. Rather than argue about prioritization of competing economic, religious, cultural, or other values, expertize in its various forms is viewed as the appropriate currency of Western democratic policy processes (Bellamy, 2006). As such, over the past century technocrats have wielded greater power to influence policy decisions than laypeople. This is epitomized by the technocracy movement (Akin, 1977; Kopp, 1991; Stockbridge, 1933) wherein progressives argued that experts should govern, particularly with regards to the economy and infrastructure. The lasting influence of this tradition is seen in our modern preference for cost-benefit analysis, econometric evaluation of policy alternatives, and the conceptual separation between the messy policy decision process and the more technocratic administrative state. This love affair with expertize is based either implicitly or explicitly on the idea that if the policy process were imbued with objective knowledge and politics were removed, we would make better collective decisions. We have essentially made synonyms of the knowledge-deficit model and collective decision making.

Events of the current decade should be a cautionary tale with regard to the eventual outcomes of placing expertize at the center of political decisions. Scholars and scientists alike now frequently 
lament the politicization of science. Robert Cox (2010) argues that this politicization was inevitable when expertize began to dominate policy discourse. When experts play a pivotal role in the identification of problems, the articulation of policy alternatives, and the debate over policy solutions (Kingdon, 2003), they and their knowledge (i.e., science) are the target that opponents attack to thwart unwanted policies. In order to target the political goals or policies that they disagree with, opponents-whether they be driven by populist ideology, corporate goals, or other motivations - must directly target the very scientific underpinnings of the debate. This observation is more prescient than ever, whether about climate science, vaccine safety, hurricane predictions, or other forms of evidence that are now routinely 'debunked' in an effort to undermine science itself. Scientists, therefore must navigate this realm of science communication within the policy sphere with a keen sense of awareness about their own goals as well as the potential pitfalls associated with politicizing issues.

When one takes heed of the deficiencies of KDM it becomes quite evident that a new approach to communicate scientific evidence within policy processes is needed. We propose better storytelling to fill that need.

\section{The narrative policy framework and the significance of storytelling}

The expert, whether it is the rational policy analyst or the objective scientist, is usually in the business of searching for the answer. In politics, where scientific evidence is usually fitted to beliefs and values for strategic purposes, rarely is the answer available. Moreover, policy problems are complex and almost never monocausal. This complexity interacts with the scientific mandate to speak to other scientists in levels of uncertainty (e.g., $p<.05$ ), thereby opening argumentative causeways to challenge scientific findings. This is politics 101, really. Focusing on the uncertainty of science to undermine scientific evidence is pretty much standard procedure for any political opposition that scientific findings run counter to, such as we have seen in tobacco policy and climate policy (Oreskes and Conway, 2011) and countless other examples. These conditions culminate in what public policy scholars label a condition of ambiguity (Kingdon, 2003). Ambiguity, as we define it here, is the idea that there are many plausible answers to policy problems. For example, crime can be argued to be the result of poor individual choices just as it can be argued to be the result of environmental circumstances, and so it goes for all politicized issues. Scientific evidence will help, but as we show above in relation to utilization and science communication, it will likely not win the day by itself. One must make sense of the complexity by socially ordering the ambiguity in a way that resonates with the intended audience. The primary means by which human beings order their social reality is through narrative. You need to tell a compelling story.

Media talking heads, political pundits, and campaigners will all laud the importance of narratives, arguing that one must control the narrative, ${ }^{1}$ get out in front of the narrative, ${ }^{2}$ or spin the narrative. ${ }^{3}$ But what they will not tell you is what a narrative is, exactly, leaving the would be narrator with only a vague conception that narratives are the things people say. This is not very helpful. Thus, to maximize the persuasiveness of the communication of scientific evidence, one must begin with a clear understanding of what a narrative is; one must be able to disaggregate its component pieces and have reasonable expectations about what will happen when specific component parts of the narrative are varied (e.g., switching out one villain for another). A recent scientific approach to understanding narrative in public policy titled the Narrative Policy Framework (NPF), offers a means to do just that.
The NPF emerged from a long tradition of research and commentary within fields such as English (e.g., Herman, 2003), Psychology (Polkinghorne, 1988), communication studies (Kinder, 2007), and Political Science (Berinsky and Kinder, 2006) wherein the role and importance of storytelling in social and political life has been explored. The NPF establishes an empirical approach to measuring the influence that narratives have in the policy process by first defining a narrative as having a setting, characters, plot and a moral of the story (see Shanahan et al., 2017).

1. Setting: The setting includes ideas, facts, and other policy consequential characteristics related to the issue. Some of these objects are relatively fixed and stable, such as constitutional parameters. Other elements of the setting, such as scientific findings, can be contested with variable meanings for different actors.

2. Character: Characters are the emotional engine of policy stories (e.g., Jones, 2014b). They include victims who are hurt. Villains are responsible for the hurt, and heroes that bring promise of reprieve for the victim.

3. Plot: The plot of a narrative positions the characters within the setting across time and space, establishes relationships between characters, and determines what elements of the setting are active, what elements are dormant, or altogether left out.

4. Moral: Stories are told to make a point. That point is what is referred to as the moral, or what the listener is supposed to take with them. If told well, the story should maximize the ability to recall the moral. In a policy narrative, the moral of the story is often a solution to the policy problem.

One way to think of the components above is that they organize emotions within a narrative. How these components are ordered in terms of why the villain causes harm, the vulnerability of the victims, depiction of a problem, and what can be done about it, among other qualities of a good story, all matter. It is these emotional components of a story that are most memorable, not references to scientific evidence. While the NPF does not have all of the answers regarding how different configurations of components perform within the near innumerable policy contexts in which they may arise, the public policy literature and findings produced by the NPF provide guidance about telling compelling stories containing scientific evidence. We offer several categories of findings within the NPF that should help in constructing these stories, followed by a step-by-step guide for story construction. We later illustrate this guide with examples from the US vaccine controversy.

Before proceeding, however, it is worth illuminating a potentially important distinction that may not be obvious to the reader. A common distinction drawn in the public policy literature that addresses policy narratives is a distinction made between persuasion and mobilization (see Peterson and Jones, 2016). One way to understand this distinction is that persuasion is intended to convince a person or change a person's mind; mobilization is intended to activate predispositions to cultivate action, usually by drawing existing preferences to the forefront of a person's thoughts and compelling them to prioritize them. While the two are obviously not mutually exclusive, we focus here on narrative persuasion. We do so for two reasons. First, published NPF studies have exclusively examined persuasion and have not specifically examined mobilization. Second, in our opinion, mobilization falls more in line with advocacy roles and is less aligned with the communication role that science communicators have envisioned for themselves, which is to rationally persuade (which is arguably the motive behind $\mathrm{KDM}$ ). Consequently, in what follows it can be assumed by the reader that we are speaking primarily to narrative persuasion. 
Congruence. One of the more consistent findings within NPF research is that whether or not a story is congruent (whether or not it fits with an individual's pre-existing understanding of the world) matters in terms of a story's persuasiveness. Congruence has been shown to strengthen existing beliefs (Shanahan et al., 2014), generate empathy (Niederdeppe et al., 2015), is more likely to be remembered as the narrator intended (Jones and Song, 2014), and also makes it more likely that new policies are accepted (Lybecker et al., 2013; McBeth et al., 2014). To establish congruence a story must contain language, symbols, causal structures, and other content that the audience recognizes as related to their preferred understanding of the world and themselves. The rub, however, is figuring out exactly what the operating belief system or value is for a given audience with a given issue.

When determining the operating value system it is best to begin with the question, is this issue already politicized? If so, then starting with ideology is a good bet and determining how conservatives and liberals understand the stories related to your issue can be relatively easy to discern by reviewing the ubiquitous academic literature, blogs, websites, and political commentaries written on the issue. If, however, the issue is not already politicized or the operating value system is something other than ideology, then it can be more difficult to establish congruence. As ideologies are often institutionally forced mixtures of beliefs (e.g., conservative libertarians and evangelical Christians are quite different), it may be the case that your issue is governed by something more nuanced such as orientations to the environment (e.g., Dunlap et al., 2000), views of citizenship (e.g., McBeth et al., 2014), cultural predispositions (e.g., Thompson et al., 1990), idiosyncratic regional beliefs (e.g., McBeth et al., 2005), or a myriad of other possibilities. The academic literature might be helpful here in that social scientists may have already pinned down the operating belief system in a peer reviewed journal article somewhere. In most cases, however, it will likely be a judgment call that you make before beginning the creation of your narrative.

Characters. The NPF has produced findings that are helpful when casting characters, especially as related to the hero. Heroes are the engines of policy stories as they both generate and accumulate positive emotion. NPF research finds that people tend to like the hero more, and the more they like the hero, the more likely they are to be persuaded by the narrative's arguments and calls to action (Jones, 2014b; Jones et al., 2017). Picking a hero that is congruent, trustworthy, and compelling is thus essential. Villains draw ire and generate negative emotions, and while the NPF has produced mixed results on what persuasive function they have, it is likely they play an important role, albeit a moderating one that is likely secondary to victims and heroes (Zanocco et al., 2017). Villains are responsible for the harm done to victims and as such even if they do not play a direct role in persuading, they help structure the plight of the victim and the obstacles that heroes must overcome. Victims draw our sympathy in a story, but not all victims are equal. Thinking in terms of congruence one can easily imagine a victim for one person being a deviant villain for another. For example, convicted felons stripped of their franchise find mixed sympathies as a victim for many in the US (Manza et al., 2004). When casting victims, it is also better to cast individuals as opposed to aggregate statistics (Small et al., 2007), although narrating victims in conjunction with statistics might be a useful strategy. It is also likely true based on this line of argument that a clear-cut victim such as a child is less ambiguous to audiences than a victim such as a prisoner or a politician, both of whom likely conjure different emotions with different audiences. All of the emotions bound within characters and their relations to one another should be carefully considered. Generally speaking, however, eliciting positive emotions is preferable to eliciting negative emotions, which may promote apathy or despair (Pidgeon and Fishoff, 2011).

Plot. Within narratives, plots establish character relationships between each other and the setting-as well as across time and space. Within policy narratives about policy issues, plots also define the problem. They establish causality (so in this sense, even science has a plot) (Stone, 2011), determine the villain(s) to blame, what that villain's intentions are (nefarious and intentional or perhaps good intentioned but unintended outcomes), and of course situate the scientific evidence within the setting and its relationship with characters. The NPF has shown mixed results when it comes to understanding plot. Studies have found that intentional causal scenarios, where the villain is acting maliciously, are effective (Crow and Berggren, 2014; Shanahan et al., 2014). However, at least one other study has found that mechanical causal scenarios, where the villain is a system that generates problems unknowingly can also be effective with populations with have high levels of political knowledge (Jorgensen et al., 2017). Plot is another aspect of narrative that appears quite context-dependent and most likely related to congruence.

Evidence. Scientists view science as compelling evidence upon which to base policy, but it is important to recognize that evidence actually comes in many forms, not just science. Recall that earlier in this article we defined evidence as "an argument or assertion backed by information" (Cairney, 2016, p 3). Said evidence was considered scientific if it was backed by the scientific method. People, however, do not usually have to conduct actual science to accept scientific evidence as legitimate; rather, they trust the science findings reported to them by some source or another or they do not. Some will trust the science simply because it is science, but not all, which is to show that sources other than science also convey legitimacy. For example, people will elevate statements from trusted sources such as their spouse, priest, or favorite movie star to the level of legitimate evidence; they often ascribe increased legitimacy to statements containing numbers or statistics (Stone, 2011); appeals to the law, or morality are also often seen as legitimate forms of evidence. Consequently, within the NPF, evidence is divided into five useful categories: scientific findings, statistics, polls, legal, and ipso dictum (Smith-Walter et al., 2016), where ipso dictum are overt appeals to an authority such as a religious figure or a celebrity whose status and position count as legitimacy with some populations. All of these forms of evidence count, and do so in varied ways with different audiences, usually in terms of congruence. The key to understanding how people understand evidence--what counts and for whom--is trust. In order for evidence to be viewed as legitimate, the source must be trusted.

Using the five categories of evidence provided by the NPF, evidence can be used to help establish the setting of the narrative (e.g., time, history, and politics) or the problem definition and causality (e.g., data on the severity, causes, or consequences of a problem). Importantly, NPF research has found that advocacy groups frequently pair their evidence with one or more of the other narrative elements, such as characters (Schlaufer, 2016; Smith-Walter et al., 2016). Such pairings are likely to bring the emotional attachment of a narrative element, such as a villain or victim, and make the evidence more memorable (e.g., Jones and Song, 2014). For the scientific narrative, it is critical that evidence be considered in every phase of narrative development. Why is it 
being used? To what end? By whom? Who does it benefit? Who does it hurt? Most importantly, do not just think of good science as the only form of evidence that counts because your audience, in most situations, will not pay science the same obeisance.

Figure 1 (Jones and Peterson, 2017) illustrates our model of storytelling. By identifying the audience, the narrator can calibrate narrative congruence. By next casting characters that are compelling and/or aligned with audience beliefs the narrator can attempt to capture emotion and the attention. Developing the problem definition in a manner consistent with evidence and prior beliefs (both the audiences and the narrator's) can also help increase the persuasiveness of a narrative. Finally, there should be a moral of a story (a solution to the problem) if the narrative is to move beyond critique into the realm of solving problems.

\section{Narratives, science, and persuasion: examples of vaccine narratives}

In what follows we offer two real world illustrative breakdowns of narratives related to the contentious issue of childhood vaccine safety. These illustrations were chosen not because they originate from actual scientists, but because, in our view, the communications represent a likely-to-be told story mixing scientific evidence with story elements that are easy to follow. For each example below we touch on the four steps presented in the model above to illustrate how this model can help a narrator construct a compelling scientifically focused evidence-based story. Due to space considerations, we first offer a short summary of each while providing a full rendering of the story in the Supplementary Material. Each analysis is meant to stand alone, but we do strongly encourage the reader to read the original sources. To the best of our knowledge, each example uses accurate evidence to support the story, which is a key consideration given that we have argued in support of persuasive but accurate science communication.

The U.S. vaccine controversy. Childhood vaccines are widely accepted in the medical community as safe and effective for preventing disease (Gust et al., 2008). Global pandemics such as smallpox, polio, pertussis, and diphtheria have either been eradicated from much of the world, or have become less prevalent as a result of widespread adoption of childhood vaccines (Conis, 2014). Vaccination safety in the U.S. has been a public concern since the late 1990s, when medical literature appeared to indicate that a relationship existed between autism and the MeaslesMumps-Rubella (MMR) vaccine (Wakefield, 1999). The so-called "thimerosal scare," which focused on childhood vaccine safety, has resurfaced in recent years with increasing anxiety about immunizations beyond MMR (Conis, 2014). According to the Centers for Disease Control (CDC), the number of individual cases of measles quadrupled in 2014 due to lower childhood vaccination rates in the U.S., with the majority of parents who opted-out of vaccinations stating that their choice was based on fears of vaccine safety, or due to religious beliefs. The CDC warns that in some areas of the U.S., herd (or community) immunity may be threatened because vaccine rates are now below critical threshold levels (Centers for Disease Control and Prevention, 2015). In 2015, a measles outbreak in Disneyland (California) captured national attention and led to less permissive state laws related to vaccine exemptions in several states. ${ }^{4}$ A 2017 measles outbreak in Minnesota that primarily struck Somali families garnered more recent headlines and is the subject of one of the examples we use below. ${ }^{5}$

We next introduce two examples of narratives that were originally published in mainstream media and therefore intended

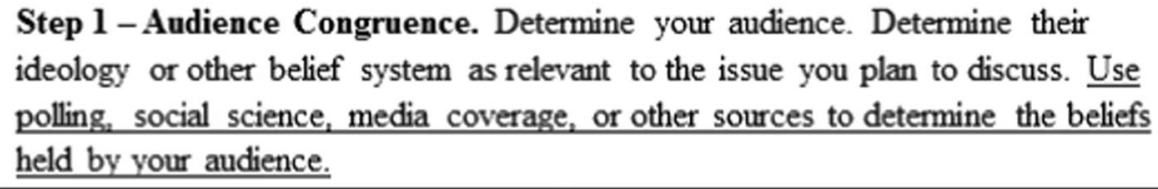

Step 2 - Cast your Characters. Based on the audience's beliefs and the issue, what characters might be the most effective heroes, villains, or victims to reach the audience and persuade them?
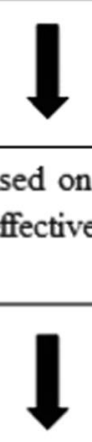
Step 3 - Define the Problem and Plot the Story. Determine the best way to explain the problem, causes, or possible solutions. Use evidence to explain the problem, keeping in mind what you discovered in Step 1.

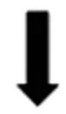

Step 4-Argue the Moral. Clearly propose the moral - or solution - to your story. Again, remember congruence here and provide evidence to support your argument. 
to appeal to wide audiences where congruence is difficult to assess. In both of the narratives presented here, we begin with the understanding that they are intended for broad audiences (Step 1). From public opinion data, we know that the overwhelming majority of American adults believe that even the measles vaccines-the center of the MMR controversy started by Dr. Wakefield-is safe (Centers for Disease Control and Prevention, 2015). There have also been several scientific studies that speak to the persuasiveness of various vaccine narrative strategies that should be heeded when evaluating these narratives. At least one study has shown that neither narrative nor technical communication is more persuasive than the other (Nyhan et al., 2014), while other studies have shown that the use of trusted sources (Freed et al., 2011) and appealing to the scientific consensus (van der Linden et al., 2015) have shown some persuasive promise for pro-vaccine messaging. We can also safely assume that parents are motivated by a desire to protect their children (an example of issue congruence), and therefore those who opt-out often do it for fear-based motivations related to the desire to protect their children. Our narratives, therefore, should both strive to appeal to these basic beliefs that vaccines are generally safe and that parents want to protect their children.

Example 1: The anti-vaccine doctor as villain. In 2017, Minnesota faced the largest measles outbreak since 2000 in the U.S. As of June 1, 2017, there were 73 confirmed cases and 8250 exposures. ${ }^{6}$ The measles outbreak primarily impacted a SomaliAmerican community, which provides a compelling emotive hook to the story being told. The example narrative chosen here was written for Vox (Supplementary Material-Appendix A), an online publication.

Step 2: Cast your characters. Dr. Andrew Wakefield, the doctor who published the now-discredited study about the link between autism and the MMR vaccine, figures prominently in this narrative. Wakefield is a complicated villain because doctors are likely sympathetic characters and more often generically viewed as heroes. On the other hand, Wakefield's reputation and history of falsifying science likely make him a compelling villain, given his betrayal of such a revered profession. The Somali community -and particularly Somali children-is the victim to Wakefield's villain, which is an effective casting due to the victimization of children and disadvantaged immigrants. A missing element to this narrative is the hero character, which as we mentioned earlier can be one of the most compelling facets of a policy narrative. More specifically, Dr. Wakefield and the Somali children victims, coupled with a compelling hero may be the most persuasive combination of character types for this narrative. For example, by including a description of the doctors or nurses who are working to care for the Somali children, helping to educate, or listening to and addressing the Somali community's fears and helping them to make sound vaccine choices, these hero characters could provide a sense of hope and empowerment that a focus on villains tends to strip away from a narrative.

Step 3: Define the problem and plot. The narrative is about a serious outbreak of measles among Somali immigrants in Minnesota. Dr. Wakefield, the villain, has been spreading anti-vaccine information among Somali immigrants. Some argue that his misinformation campaign has led to a decrease in vaccination rates, putting the immigrant community at risk for outbreaks such as the one that happened in 2017.

“Anti-vaccine groups have helped fuel Minnesota's largest outbreak of measles in nearly 30 years, with 58 confirmed cases since the outbreak was identified in April. Most of the cases are occurring among unvaccinated Somali-American children in Minneapolis, whose parents have been the targets of anti-vaccine propagandists, according to the state health department."

And the most notable propagandist is the central villain in the story:

"One of the most noteworthy fearmongerers is Andrew Wakefeld, the discredited doctor who introduced the bogus idea that vaccines and autism are linked in a paper in 1998, The Lancet study. (Since then, the paper has been retracted, Wakefeld has lost his medical license, and studies in thousands of children have shown the vaccine is safe.). Along with other vaccine deniers, Wakefeld has continued to spread fears about the measles-mumps-rubella vaccine through public lectures and outreach campaigns in Minnesota over the past several years, according to reports in the Star Tribune. He also defended his fearmongering in the Washington Post by saying he's just giving concerned parents information they want."

In this narrative, evidence is provided in a sequence of seven facts, including: (1) measles was eliminated in the U.S. in 2000 but because of vaccine refusal, cases keep popping up, (2) there's no link between the MMR vaccine and autism, (3) measles is deadly and typically strikes children, (4) a photograph of measles and a statement that there is no treatment, (5) measles is entirely preventable, (6), one case of measles can lead to 18 additional cases because it is so contagious, and (7) health officials fear that vaccine refusal is on the rise. Each of the seven points is supported by additional evidence, including statistics and statements by health officials and portrayed in relation to a compelling victim, children.

Again in this narrative, the plot of the story could be improved by using hero characters to give some sense of a possible solution (leading to Step 4, next), and provide optimism for readers.

Step 4: Argue the moral. This narrative falls short in clearly presenting a moral of the story. Implicitly, the moral is that either policy makers should remove some of the exemptions that presently exist in vaccine requirements or that we need more education to make sure that Wakefield and his stories do less damage. The narrative could be improved with a direct moral that would help improve the problem that is clearly and compellingly presented in Step 3. That moral-or solution-could be policyfocused and delve into the various options that lawmakers have to protect children or ensure that parents have access to accurate medical information. Or, the moral could also focus attention on actions of the possible heroes, whether those heroes are the medical professionals working to protect, educate, and heal the sick families, or whether those heroes are the parents themselves who are working hard in a new country to learn about what they need to do for their children, but who occasionally fall into traps like those laid by Dr. Wakefield. In each of these possible morals the narrative gains a significant missing narrative element discussed earlier in this article. Each possible addition would add a clear solution to the problem and for the victim, and a sense of hope and optimism. These elements neatly map onto NPF findings that suggest messages in-line with prior beliefs, positive characters, and clear character typologies are more likely to persuade audiences.

Example 2: Anti-vaccine celebrity as villain. The next example narrative was written in 2013 by a writer for the New Republic (Supplementary Material-Appendix B) who contracted whooping cough. On the heels of disease outbreaks such as the 
measles outbreak at Disneyland and others, the public dialog had focused on the role that anti-vaccine activists had played in the falling rates of childhood vaccinations. Again, with this example, we assume a broad audience and the same examples of issue congruence as above.

Step 2: Cast your characters. Similar in nature to Example 1, the second narrative uses a villain, but this time she is celebrity antivaccine activist Jenny McCarthy who claims that her son developed autism after he received routine childhood vaccines. She is an effective villain for this narrative due to her reputation as antiscience and her unsympathetic character type of a Hollywood celebrity that is out-of-touch. The second dominant character is the reporter herself as the victim, with common references to generic children victims as well. She is an effective victim because she can accomplish a tongue-and-cheek narrative about a victim of disease which a narrator would struggle doing unless poking fun at herself. This works well given that the narrator intentionally chooses a slightly humorous tone of writing. As with Narrative 1, the villain/victim combination might not be as powerful as it would be if the characters were coupled with a hero who could help solve the problem. These heroes could be policymakers, medical professionals, or even other celebrities who counter the message that McCarthy pushes.

Step 3: Define the problem and plot. In this narrative, the reporter writes in first-person about developing whooping cough and depicts herself as the victim of McCarthy's anti-vaccine agenda. In her humor-tinged evidence-based essay, "I've Got Whooping Cough. Thanks a Lot, Jenny McCarthy," Julia Ioffee writes:

"Led by discredited doctors and, incredibly, a former Playmate [McCarthy], the movement has frightened new parents with claptrap about autism, Alzheimer's, aluminum, and formaldehyde. The movement that was once a fringe freak show has become a menace, with foot soldiers whose main weapon is their self-righteousness. For them, vaccinating their children is merely a consumer choice, like joining an organic food co-op or sending their kids to a Montessori school or drinking coconut water... So thanks a lot, anti-vaccine parents. You took an ethical stand against big pharma and the autism your baby was not going to get anyway, and, by doing so, killed some babies and gave me, an otherwise healthy 31-year-old woman, the whooping cough in the year 2013. I understand your wanting to raise your own children as you see fit, science be damned, but you're selfishly jeopardizing more than your own children."

Within this inadvertent plot, evidence is used throughout to support the argument being made that anti-vaccine activists (mostly parents) who say they are taking a stand against 'big pharma' and vaccine safety are putting many people at risk for serious illnesses. But evidence is also used to communicate how serious measles is, despite the fact that we often ignore such diseases due to the luxury of modern medicine and vaccines that protect against such outbreaks.

"Pertussis, named after the elegantly latinate bacterium Bordetella pertussis, starts the way of any cold or mild flu. Then, a week or two later, the coughing starts. That's because $B$. pertussis glom onto and paralyze the cilia, the lash-like filaments in your airways that clear it out of mucus, the stuff your body uses to trap and get rid of the infection. The bacterium also emits various toxins, some of which mask the infection and don't allow your immune system to recognize and attack it. It therefore takes longer for your body to clear it and leaves your trachea so inflamed that it is sensitive even to things like water and air, leading to those wild coughing bouts that sound like this in kids and this in adults. And while my having pertussis at my age seems absurd, it can also be tragic: In babies, the infection can easily be fatal."

Step 4: Argue the moral. The author draws the reader in with her own story and the characters and conflict she establishes, then expands to support the argument with statistics, facts, and stories such as the Disneyland measles outbreak, before she concludes again with her own point-of-view. The moral she argues, however, is more critique than solution. Her pointed criticism of antivaccine parents and their 'big pharma' fight does not go as far as proposing a solution from a policy, political, or personal stand. To improve this narrative, combining a heroic character with a clear moral, or solution, could move this narrative from simple critique to something more akin to a forceful call-to-action. She could do this without losing her notable cheeky tone of the narrative. She could do this by calling on a clear and compelling hero for action. Given the tone and the villain she has cast, a particularly effective solution might be from another celebrity (i.e., someone with a cause similar to Leonardo DiCaprio's advocacy for the environment or George Clooney's fight to raise awareness about Darfur). Another effective combination for her chosen tone and story could be a wealthy philanthropist who is fighting to protect children from disease, such as Bill and Melinda Gates are doing with their vast wealth. These celebrity characters and solutions provide nice hooks for her already cheeky tone and could increase the persuasive potential for the narrative.

\section{Conclusion}

The two examples provided above illustrate our main points. First, understanding the audience and clearly articulating a problem is essential. Without a clear understanding of the audience your narrative is likely to be lost, misinterpreted or worse, it could backfire. In both of these narrative examples, intended for different and yet broad audiences, the narrators take a traditional journalistic tone (Example 1) and a younger more cheeky columnist's tone (Example 2). Regardless of tone, both narratives have the potential to speak to their audiences and sway opinion about vaccines, but neither as originally written, has likely maximized its potential in accomplishing that goal. Second, characters can package emotion and help tell the story of a problem by attaching emotion to elements of the setting through their relationships with each other and the problem, as depicted in both examples above. Narrators in certain topical areas like vaccines, and perhaps also like climate change or other areas where there are significant numbers of anti-science voices in the public sphere, seem to focus on villains and victims as shown in our examples. We argue that by also focusing on heroic characters that narrators might have a better chance of reaching their audience with more optimistic messages that might help shape understanding of science issues. These characters can help shape the moral of the story as well, wherein the narrator can construct a moral that is a clearer call-to-action (in opinion pieces like Example 2) or policy solution (like Example 1). Third, evidence can be effectively woven into narrative and this can be done by scientists and advocates alike. As Robert Krulwich argued in 2008, scientists must learn to tell stories, both about the importance of the scientific endeavor and their research topics, and also about the data that must be translated and understood in order for it to become policy relevant.

Understanding the advice above and being able to implement it are likely two different things. One of the major prerequisites of our narrative advice is that one must be able to maneuver 
symbols, arguments, characters, and the like strategically. Therein is the difficulty. Because if what we argue about narrative is true of your audience, it is also true of yourself. The stories you will want to tell will be stories that emanate from you as expressions of you, your beliefs, and your identity. For example, if you are an ardent libertarian, perceiving free choices as a problem will be difficult. Thus, your abilities as a storyteller, while not only constricted by the professional and procedural boundaries of good science, will also be constrained by your beliefs and how willing you are to manipulate them. In the end, your ability to tell a good story embedded with scientific evidence will hinge to a greater or lesser extent on your ability to acknowledge your own beliefs in a somewhat dispassionate manner, embrace the perspectives of others, and view them all from the outside, treating elements strategically, and to do so in the name of science. We suspect this will not be easy, but then again, what hero's journey is?

Received: 12 June 2017 Accepted: 15 November 2017

Published online: 22 December 2017

\section{Notes}

1 Controlling The Narrative Of Failure. Huffington Post UK. http://www.

huffingtonpost.co.uk/dr-ioannis-glinavos/controlling-the-narrative_b_16431720.html.

2 Sticky Narratives and "getting control". Valico Group. http://valicogroup.com/powermeaning-narrative/.

3 Media basher Trump calls media to defend health care failure. CNN. March 24, 2017. http://money.cnn.com/2017/03/24/media/trump-media-healthcare/index.html.

4 How California got more children vaccinated after the Disneyland measles outbreak. Los Angeles Times. April 13, 2017. (http://www.latimes.com/local/lanow/la-mevaccination-explainer-20170413-story.html).

5 Measles outbreak in Minnesota surpasses last year's total for the entire country. Washington Post. June 1, 2017. www.washingtonpost.com/national/health-science/ imams-in-us-take-on-the-anti-vaccine-movement-during-ramadan/2017/05/26/ 8660edc6-41ad-11e7-8c25-44d09ff5a4a8_story.html?utm_term=.71e87548abc7. 6 Ibid.

\section{References}

Akin WE (1977) Technocracy and the American dream: the technocrat movement, 1900-1941. Univ of California Press, Oakland, CA

Bardach E, Patashnik EM (2015) A practical guide for policy analysis: the eightfold path to more effective problem solving. CQ press, Washington, DC

Bellamy R (2006) Still in deficit: rights, regulation, and democracy in the EU1. Eur Law J 12(6):725-742

Berinsky AJ, Kinder DR (2006) Making sense of issues through media frames: understanding the Kosovo crisis. J Polit 68(3):640-656

Cairney P (2016) The politics of evidence-based policy making. Springer, New York, NY

Conis E (2014) Vaccine nation: America's changing relationship with immunization. University of Chicago Press, Chicago, IL

Cox R (2010) Environmental communication and the public sphere. Sage Publications, Thousand Oaks, CA

Crow DA, Berggren J (2014) Using the narrative policy framework to understand stakeholder strategy and effectiveness: a multi-case analysis. In: Jones MD, Shanahan EA, McBeth MK (eds) The science of stories: applications of the narrative policy framework in public policy analysis. Palgrave Macmillan, NY

Dunlap RE, Van Liere KD, Mertig AG, Jones RE (2000) New trends in measuring environmental attitudes: measuring endorsement of the new ecological paradigm: a revised NEP scale. J Social Issues 56(3):425-442

Freed GL, Clark SJ, Butchart AT, Singer DC, Davis MM (2011) Sources and perceived credibility of vaccine-safety information for parents. Pediatrics 127 (Supplement 1):S107-S112

Gust DA, Darling N, Kennedy A, Schwartz B (2008) Parents with doubts about vaccines: which vaccines and reasons why. Pediatrics 122:718-725

Healy RG, Ascher W (1995) Knowledge in the policy process: Incorporating new environmental information in natural resources policy making. Policy Sci 28 (1):1-19

Herman D (2003) Narrative theory and the cognitive sciences: Stanford Univ Center for the Study
Iyengar S (1990) Framing responsibility for political issues: the case of poverty. Polit Behav 12(1):19-40

Jones MD (2011) Leading the way to compromise? Cultural theory and climate change opinion. PS: Polit Sci Polit 44(04):720-725

Jones MD (2014a) Communicating climate change: are stories better than "just the facts. Policy Stud J 42(4):644-673

Jones MD (2014b) Cultural characters and climate change: how heroes shape our perception of climate science. Soc Sci Q 95(1):1-39

Jones MD, Flottum K, Gjerstad O (2017) Stories about climate change: the influence of language on public opinion. In: Flottum K (ed) The role of language in the climate change debate. Routledge, New York, Forthcoming

Jones MD, Peterson HL (2017) Narrative persuasion and storytelling as climate communication strategies. Oxford Research Encyclopedia of Climate Science. Retrieved 2 Dec. 2017, from http://climatescience.oxfordre.com/view/ 10.1093/acrefore/9780190228620.001.0001/acrefore-9780190228620-e-384

Jones MD, Shanahan EA, McBeth MK (2014) The science of stories: applications of the narrative policy framework in public policy analysis. Palgrave Macmillan, New York, NY

Jones MD, Song G (2014) Making sense of climate change: how story frames shape cognition. Polit Psychol 35(4):447-476

Jorgensen P, Song G, Jones MD (2017) Prospects for Campaign Finance Reform: the role of political knowledge, attitudes, and narratives in collective policy formation. Soc Sci Quar. early view. https://doi.org/10.1111/ssqu.12357

Kahan DM (2014) Making climate-science communication evidence-based. culture, politics and climate change: how information shapes our common future 203

Kahan DM, Braman D, Gastil J, Slovic P, Mertz C (2007) Culture and identityprotective cognition: explaining the white-male effect in risk perception. J Empir Leg Stud 4(3):465-505

Kahan DM, Jenkins-Smith H, Braman D (2011) Cultural cognition of scientific consensus. J Risk Res 14(2):147-174

Kinder DR (2007) Curmudgeonly advice. J Commun 57(1):155-162

Kingdon JW (2003) Agendas, alternatives and public policies, 2nd edn. Longman, New York

Kirkhart KE (2000) Reconceptualizing evaluation use: an integrated theory of influence. New Dir Eval 2000(88):5-23

Kopp JJ (1991) Edward Bellamy and the new deal: the revival of Bellamyism in the 1930s. Utop Stud 4:10-16

Krulwich R (2008) Tell me a story. Eng Sci 71(3):10-16

Lasswell HD (1970) The emerging conception of the policy sciences. Policy Sci 1 (1):3-14

Lybecker DL, McBeth MK, Kusko E (2013) Trash or treasure: recycling narratives and reducing political polarisation. Env Polit 22(2):312-332

Lynd RS (1939). Knowledgefor what. Princeton, NJ: Princeton UP

Manza J, Brooks C, Uggen C (2004) Public attitudes toward felon disenfranchisement in the United States. Public Opin Q 68(2):275-286

McBeth MK, Lybecker DL, Husmann MA (2014) The narrative policy framework and the practitioner: communicating recycling policy. In: The science of stories, Palgrave Macmillan, New York, NY, p 45-68

McBeth MK, Shanahan EA, Jones MD (2005) The science of storytelling: measuring policy beliefs in greater yellowstone. Soc Nat Resour 18:413-429

Meijerink S (2005) Understanding policy stability and change: the interplay of advocacy coalitions, epistemic communities, windows of opportunity, and dutch coastal flooding policy, 1945-2003. J Eur Public Policy 12(6):1060-1077

Monaghan M (2010) Adversarial policies and evidence utilization: modeling the changing evidence and policy connection. Ger Policy Stud 6(2):17

Niederdeppe J, Roh S, Shapiro MA (2015) Acknowledging individual responsibility while emphasizing social determinants in narratives to promote obesityreducing public policy: a randomized experiment. PloS One 10(2):e0117565

Nyhan B, Reifler J, Richey S, Freed GL (2014) Effective messages in vaccine promotion: A randomized trial. Pediatrics 133(4):e835-e842

Oreskes N, Conway EM (2011) Merchants of doubt: how a handful of scientists obscured the truth on issues from tobacco smoke to global warming. Bloomsbury Publishing, USA

Pew Research Centre (2015) 83\% say measles vaccine is safe for healthy children. PRC. Retrieved from http://www.people-press.org/2015/02/09/83-percentsay-measles-vaccine-issafe-for-healthy-children/

Pidgeon N, Fischhoff B (2011) The role of social and decision sciences in communicating uncertain climate risks. Nat Clim Change 1:35-41

Peterson HP, Jones MD (2016) Making sense of complexity: the NPF and agenda setting. In Zahariadis N (ed) Handbook of Public Policy Agenda-Setting. Edward Elger, p 106-131

Pielke Jr. R (2007) The honest broker: making sense of science in policy and politics. Cambridge University Press, Cambridge, UK

Polkinghorne DE (1988) Narrative knowing and the human sciences. Suny Press, Albany, NY

Prevention, C. f. D. C. a. (2015) Herd immunity. http://www.vaccines.gov/basics/ protection/ 
Reynolds TW, Bostrom A, Read D, Morgan MG (2010) Now what do people know about global climate change? Survey studies of educated laypeople. Risk Anal 30(10):1520-1538

Sabatier PA (1988) An advocacy coalition framework of policy change and the role of policy-oriented learning therein. Policy Sci 21(2-3):129-168

Sabatier PA, Jenkins-Smith HC (eds) (1993) Policy change and learning: an advocacy coalition approach. Westview Press, Boulder, CO

Schlaufer C (2016) The narrative uses of evidence. Policy Stud J. https://doi.org/ 10.1111/psi.12174. Accessed 20 Aug 2016

Shanahan EA, Adams SM, Jones MD, \& McBeth MK (2014) The blame game: narrative persuasiveness of the intentional causal mechanism. In: Jones MD, Shanahan EA, McBeth MK (eds) The Science of Stories: Applications of the Narrative Policy Framework in Public Policy Analysis. Palgrave Macmillan, New York, pp 69-78

Shanahan E, Jones MD, McBeth MK, Radaelli CM (2017) The Narrative Policy Framework. In: Weible C, Sabatier P (eds) Theories of the Policy Process. 4th edn, Westview Press, p 173-213

Small DA, Loewenstein G, Slovic P (2007) Sympathy and callousness: the impact of deliberative thought on donations to identifiable and statistical victims. Organ Behav Hum Decis Process 102(2):143-153

Smith-Walter A, Peterson HL, Jones MD, Marshall A (2016) Gun stories: how evidence shapes firearm policy in the United States. Polit Policy 44 (6):1053-1088

Song G (2014) Understanding public perceptions of benefits and risks of childhood vaccinations in the United States. Risk Anal 34(3):541-555

Stevens A (2007) Survival of the ideas that fit: an evolutionary analogy for the use of evidence in policy. Soc Policy Soc 6(01):25-35

Stevens CJ, Dial M (1994) What constitutes misuse? New Dir Program Eval 1994 (64):3-13

Stockbridge FP (1933) Edward Bellamy, prophet of technocracy. Am Press 51 (4):15-31

Stone D (2011) Policy paradox: the art of political decision making, 3rd edn. Norton, New York

Stoutenborough JW, Sturgess SG, Vedlitz A (2013) Knowledge, risk, and policy support: public perceptions of nuclear power. Energy Policy 62:176-184

Stroud NJ (2008) Media use and political predispositions: revisiting the concept of selective exposure. Polit Behav 30(3):341-366

Taber CS, Lodge M (2006) Motivated skepticism in the evaluation of political beliefs. Am J Pol Sci 50(3):755-769

Thompson M, Ellis R, Wildavsky A (1990) Cultural theory. Westview Press, Boulder, $\mathrm{CO}$

van der Linden SL, Clarke CE, Maibach EW (2015) Highlighting consensus among medical scientists increases public support for vaccines: evidence from a randomized experiment. BMC public health 15
Wakefield AJ (1999) MMR vaccination and autism. Lancet 354:949-950

Weible CM (2008) Expert-based information and policy subsystems: a review and synthesis. Policy Stud J 36(4):615-635

Weimer DL, Vining AR (2017) Policy analysis: concepts and practice. Taylor \& Francis, New York, NY

Zanocco CM, Song G, Jones MD (2017) Fracking Bad Guys Narrative Character Affect in Public Opinion About Hydrolic Fracturing. Midwest Political Science Association Meeting, Chicago. SSRN: https://ssrn.c/abstract=3033321

\section{Data availability}

Data sharing is not applicable to this article as no datasets were generated or analyzed during the current study.

\section{Additional information}

Competing interests: The authors declare no competing financial interests.

Supplementary information: accompanies this paper at https://doi.org/10.1057/s41599017-0047-7.

Reprints and permission information is available online at http://www.nature.com/ reprints

Publisher's note: Springer Nature remains neutral with regard to jurisdictional claims in published maps and institutional affiliations.

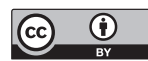

Open Access This article is licensed under a Creative Commons Attribution 4.0 International License, which permits use, sharing, adaptation, distribution and reproduction in any medium or format, as long as you give appropriate credit to the original author(s) and the source, provide a link to the Creative Commons license, and indicate if changes were made. The images or other third party material in this article are included in the article's Creative Commons license, unless indicated otherwise in a credit line to the material. If material is not included in the article's Creative Commons license and your intended use is not permitted by statutory regulation or exceeds the permitted use, you will need to obtain permission directly from the copyright holder. To view a copy of this license, visit http://creativecommons.org/ licenses/by/4.0/

(c) The Author(s) 2017 